\title{
Uncovering the pharmacological response of novel sesquiterpene derivatives that differentially alter gene expression and modulate the cell cycle in cancer cells
}

\author{
MELPOMENI G. AKRIVOU ${ }^{1}$, VERA P. DEMERTZIDOU ${ }^{2}$, NIKOLETA F. THEODOROULA ${ }^{1}$, \\ FANI M. CHATZOPOULOU ${ }^{3}$, KONSTANTINOS A. KYRITSIS ${ }^{1}$, NIKOLAOS GRIGORIADIS ${ }^{4}$, \\ ALEXANDROS L. ZOGRAFOS ${ }^{2}$ and IOANNIS S. VIZIRIANAKIS ${ }^{1}$
}

\author{
${ }^{1}$ Department of Pharmacology, School of Pharmacy; ${ }^{2}$ Department of Chemistry, Laboratory of Organic Chemistry, \\ Aristotle University of Thessaloniki, 54124 Thessaloniki; ${ }^{3}$ Labnet Laboratories, 54638 Thessaloniki; \\ ${ }^{4}$ Biogenea Pharmaceuticals Ltd., 54627 Thessaloniki, Greece
}

Received February 28, 2018; Accepted June 5, 2018

DOI: 10.3892/ijo.2018.4550

\begin{abstract}
The present study aimed to assess the pharmacological anticancer profile of three natural and five synthetic sesquiterpenes developed by total chemical synthesis. To this end, their properties at the cellular and molecular level were evaluated in a panel of normal and cancer cell lines. The results obtained by performing cytotoxicity assays and gene expression analysis by reverse transcription-quantitative polymerase chain reaction showed that: i) Among the sesquiterpene derivatives analyzed, VDS58 exhibited a notable anticancer profile within attached (U-87 MG and MCF-7) and suspension (K562 and MEL-745) cancer cell cultures; however, U-87 MG cells were able to recover their proliferation capacity rapidly after $48 \mathrm{~h}$ of exposure; ii) gene expression profiling of U-87 MG cells, in contrast to K562 cells, showed a transient induction of cyclin-dependent kinase inhibitor 1A (CDKN1) expression; iii) the expression levels of transforming growth factor $\beta 1(T G F B 1)$ increased after $12 \mathrm{~h}$ of exposure of U-87 MG cells to VDS58 and were maintained at this level throughout the treatment period; iv) in K562 cells exposed to VDS58, TGFB1 expression levels were upregulated for $48 \mathrm{~h}$ and decrease afterwards; and v) the re-addition of VDS58 in U-87 MG cultures pretreated with VDS58 resulted in a notable increase in the expression of caspases (CASP3 and CASP9), BCL2-associated agonist of cell death $(B A D)$, cyclin D1, $C D K 6, C D K N 1$, MYC proto-oncogene bHLH transcription factor $(M Y C), T G F B 1$ and tumor suppressor protein $\mathrm{p} 53$. This upregulation persisted only for $24 \mathrm{~h}$ for the majority of genes,
\end{abstract}

Correspondence to: Professor Ioannis S. Vizirianakis, Department of Pharmacology, School of Pharmacy, Aristotle University of Thessaloniki, 54124 Thessaloniki, Greece

E-mail: ivizir@pharm.auth.gr

Key words: cancer, sesquiterpenes, cytotoxicity, CDKN1, gene expression, TGFB1, gene expression profiling, pathway analysis, bioinformatics as afterwards, only the expression of TGFBl and $M Y C$ was maintained at high levels. Through bioinformatic pathway analysis of RNA-Seq data of parental U-87 MG and K562 cells, substantial variation was reported in the expression profiles of the genes involved in the regulation of the cell cycle. This was associated with the differential pharmacological profiles observed in the same cells exposed to VDS58. Overall, the data presented in this study provide novel insights into the molecular mechanisms of action of sesquiterpene derivatives by dysregulating the expression levels of genes associated with the cell cycle of cancer cells.

\section{Introduction}

Natural products represent a valuable source for developing therapeutic agents against cancer (1-5). However, the variations in pharmacological responses observed in cancer therapy, along with the development of drug resistance, represent major factors that inhibit the development of therapeutic agents with improved efficacy and safety profiles. To address these issues and achieve major clinical benefits, it is crucial to improve our understanding of the underlying molecular mechanisms of the pharmacological effects of natural products in cancer cells prior to further developing them as novel treatments $(6,7)$.

The clinical application of naturally derived sesquiterpene compounds as potential anticancer agents remains challenging with respect to their total chemical synthesis and limited understanding of their molecular behavior within cancer cells. Sesquiterpenes and their subclass, sesquiterpene lactones (SLs), represent secondary metabolites of plant-derived products; the pharmacological effects of these compounds have been found to be involved in the regulation of several complex molecular signaling pathways, the most common being the nuclear factor- $\kappa \mathrm{B}(\mathrm{NF}-\kappa \mathrm{B})$ signaling pathway (8). Diverse oxidized carbocycle members of the SLs include the germacranolides, guaianolides and eudesmanolides, which have recently attracted a great deal of attention due to their potential anticancer properties. Certain SL members were found to selectively target tumor and cancer stem cells, while avoiding 
normal cells $(9,10)$. This property has led to the application of SLs, including artemisin, thapsigargin and parthenolide, in clinical trials as therapeutic anticancer agents (11-17).

Recently, an array of arglabin analogues of the guaianolide subclass have been reported to be selective inhibitors of stem and progenitor cells related to acute myelogenous leukemia; however, the molecular mechanisms underlying their potential therapeutic properties remain unknown (17). In the development of novel innovative sesquiterpene derivatives with improved pharmacological profiles, eight structurally diverse sesquiterpenes and SLs, classified as three major subclasses (elemanes, germacranes and guaianes) were synthesized and their cytotoxicity profiles were investigated in the glioblastoma U-87 MG cell line in the present study. Among them, the compound VDS58 showed the most promising effects in a panel of human cancer cell lines (glioblastoma U-87 MG, breast MCF-7 and erythroleukemia K562), in mouse erythroleukemia (MEL-745) cells and in normal cells (human lung fibroblast MRC-5). The timedependent assessment of VDS58-treated cultures suggested that mainly U-87 MG cells are able to recover their proliferation rates after $48 \mathrm{~h}$. Gene expression analysis indicated a transient induction of cyclin-dependent kinase inhibitor $1 \mathrm{~A}(C D K N 1)$ expression within the first $24 \mathrm{~h}$ of exposure to VDS58. Notably, during this analysis, no notable alterations in tumor protein 53 (TP53) expression were observed. In addition, subsequent application of VDS58 following an initial $48 \mathrm{~h}$ of exposure revealed that cells exhibited increased expression levels of caspase-3 (CASP3), CASP9, BCL2-associated agonist of cell death $(B A D)$, cyclin-dependent kinase $(C D K 6)$, CDK inhibitor 1A (CDKNI), MYC proto-oncogene bHLH transcription factor $(M Y C)$ and $T P 53$; however, this upregulation persisted for only $24 \mathrm{~h}$. Following this, only the expression levels of $M Y C$ were maintained at high levels. This indicates that upregulated MYC expression may facilitate cancer cell proliferation, which coincides with the proliferation kinetics reported upon $48-72 \mathrm{~h}$ of exposure of cells to VDS58.

\section{Materials and methods}

Synthesis of natural sesquiterpenoids and analogs. The chemical structures and the applied method of synthesis for the production of sesquiterpenes (EA910a, EA910b, zedoarol, gweicurculactone, VDS71, VDS58, furanogermenone and EA1184) are shown in Fig. 1. The total chemical synthesis of natural substances furanogermenone, zedoarol and gweicurculactone was based on the unified synthetic protocol and methods in our previously published studies (18-21). All natural and synthetic substances were purified by flash column chromatography with Merck silica gel 60 (particle size, 0.040-0.063 mm; EMD Millipore, Billerica, MA, USA). The purity of all compounds was established by nuclear magnetic resonance on a Bruker $300 \mathrm{AM}$ (Bruker Corporation, Billerica, MA, USA) and Agilent $500 \mathrm{MHz}$ spectrometer and a high-resolution mass spectra recorder with an Agilent Electrospray ionisation time-of-flight mass spectrometer (Agilent Technologies, Inc., Santa Clara, CA, USA). All tested compounds had purity levels of $>95 \%$.

Cell cultures. The previously established cancer U-87 MG, MCF-7, murine erythroleukemia FLC clone 745 (MEL-745) and $\mathrm{K} 562$ cell lines, and a normal MRC-5 cell line, were obtained, stored and used in a routine manner $(22,23)$ in the Laboratory of Pharmacology, School of Pharmacy, Aristotle University of Thessaloniki (Greece) $(<25$ passages were applied). The murine erythroleukemia MEL-745 cells were obtained from Dr C. Friend (Division of Cytology, The Sloan-Kettering Institute for Cancer Research, New York, NY, USA) (24) and were cultured as described by our previous study (25). Regarding the dispute on the misidentification of U87 MG (26), the U87 MG cell line used in this study is a clone originating from that established at the University of Uppsala (Uppsala, Sweden). Malignant U-87 MG (human epithelial glioblastoma grade IV astrocytoma), MCF-7 (human breast cancer) and MEL-745 cells, along with the normal MRC-5 (human fetal lung fibroblast) cells, were cultured in Dulbecco's modified Eagle's medium (DMEM) supplemented with $10 \% \mathrm{v} / \mathrm{v}$ fetal bovine serum (FBS) and $100 \mu \mathrm{g} / \mathrm{ml}$ penicillin and streptomycin. K562 (human leukemic) cells were cultured in Roswell Park Memorial Institute (RPMI)-1640 medium. Cells were maintained in culture $\left(37^{\circ} \mathrm{C}\right.$ in $\left.5 \% \mathrm{v} / \mathrm{v} \mathrm{CO}_{2}\right)$, and were passaged every $2-3$ days when $75-80 \%$ confluence was achieved using trypsin-EDTA $(0.25 \% \mathrm{w} / \mathrm{v})$, for the attached cultures. Trypsin-EDTA, DMEM, RPMI and FBS were purchased from Thermo Fisher Scientific, Inc. (Waltham MA, USA).

Cytotoxicity assessment. In all experiments, the new synthesized sesquiterpene compounds were tested by dissolving them in DMSO prior to application to the various cell cultures. The final concentration of DMSO was $\leq 0.1 \%$, which had no effect on cell proliferation (data not shown). The malignant (U-87 MG, MCF-7, K562 and MEL-745) and normal (MRC-5) cell lines were seeded in 24-well plates at an initial concentration of $1 \times 10^{5}$ cells $/ \mathrm{ml}$. For the attached cultures (U-87 MG, MCF-7 and MRC-5), cells were allowed to attach for 3-4 h (at $37^{\circ} \mathrm{C}$ in $5 \% \mathrm{v} / \mathrm{v} \mathrm{CO}_{2}$ ) prior to the addition of the sesquiterpenoids. The specified concentrations used in the cultures were between $1 \times 10^{-7}$ and $1 \times 10^{-4} \mathrm{M}$. Cells were grown in the presence of the molecules for $48 \mathrm{~h}$ prior to the cell proliferation being measured with Neubauer counting chambers under an optical microscope (x10 magnification). Subsequently, the calculation of the half-maximal inhibitory concentration $\left(\mathrm{IC}_{50}\right)$ values of each compound for a specific cell line was estimated. Moreover, cell death within cell cultures was also determined using the Trypan blue dye-exclusion method, as previously described (23).

Cell pretreatment and washout experiments. Cytotoxicity was further assessed through the re-application of pretreatment and washout experiments using human malignant U-87 MG and normal MRC-5 cell cultures, respectively. The cells were pretreated for 24 and $48 \mathrm{~h}$ with the previously calculated $\mathrm{IC}_{50}$ concentrations of VDS58. VDS58 is a guaiane sesquiterpene that was synthesized by our group in the Laboratory of Organic Chemistry of the Aristotle University of Thessaloniki, starting from the commercially available (R)-carvone and following an 12-step route $(20,21)$. The re-application of VDS58 to U-87 MG cells was achieved by adding fresh DMEM containing the $\mathrm{IC}_{50}$ concentration of VDS58 to the cells. The replenishment of the MRC- 5 cell population and the removal of VDS58 

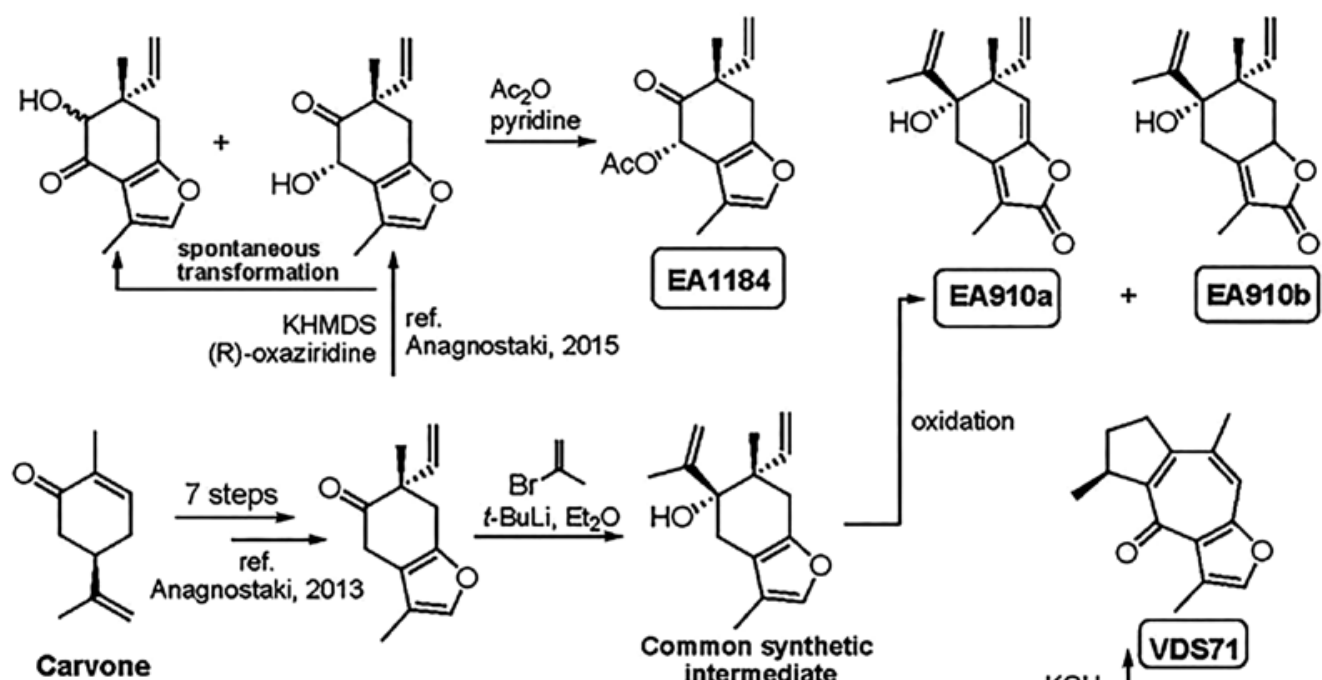

oxidation
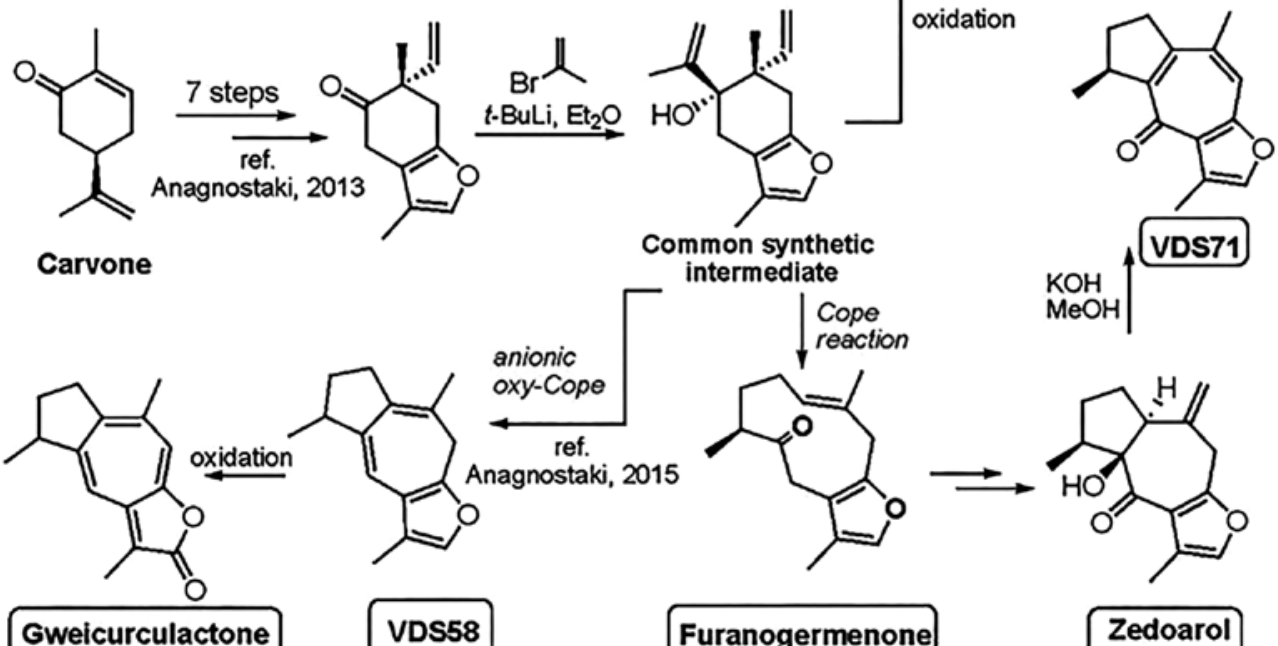

intermediate

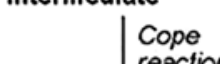

Cope
reaction
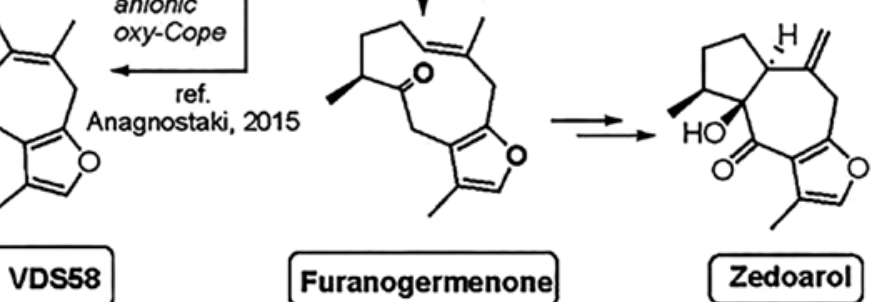

Furanogermenone

Zedoarol

Figure 1. Chemical structures of synthetic sesquiterpenes.

from the cultures were achieved by washing out the cells twice with PBS and then incubating them with fresh DMEM in the absence of drug treatment. MRC-5 and U-87 MG cells were then cultured for 96 and $120 \mathrm{~h}$, respectively. The assessment of cell proliferation and death in the cultures was performed every $24 \mathrm{~h}$ using the aforementioned methods.

$R N A$ extraction and reverse transcription-quantitative polymerase chain reaction ( $R T-q P C R)$ analysis. Total cytoplasmic RNA isolation from U-87 MG and K562 cells, and the two-step RT-qPCR analysis (kit KK4602; Kapa Biosystems, Wilmington, MA, USA) were performed as previously described (22). The following primer sequences were used to amplify the indicated genes: $\beta$-actin $(A C T B)$ forward, 5 '-ttgctgacaggatgcagaag-3' and reverse, 5'-tgatccacatctgctggaag-3'; BCL2 associated X apoptosis regulator $(B A X)$ forward, 5'-tctgacggcaacttcaactg-3' and reverse, 5'-gaggaagtccaatgtccagc-3'; BCL2 apoptosis regulator (BCL2) forward, 5'-acttcgccgagatgtcca-3' and reverse, 5'-caaagaaggcc acaatcctc-3'; CDKN1 forward, 5'-gagcgatggaacttcgactt-3' and reverse, 5'-gtgggaaggtagagcttggg-3'; CASP9 forward, 5'-tcgaagc caaccctagaaaa-3' and reverse, 5'-cctccagaaccaatgtccac-3'; $B A D$ forward, 5'-cagatcccagagtttgagcc-3' and reverse, 5'-ctgctcctgctg gtgactg-3'; CASP3 forward, 5'-ggttcatccagtcgetttgt-3' and reverse, 5'-aattctgttgccacctttcg-3'; $C D K 4$ forward, 5'-accagatggcactta caccc-3' and reverse, 5'-ccacagaagagaggctttcg-3'; $C D K 2$ forward, 5'-ttgtcaagctgctggatgtc-3' and reverse, 5'-tgatgaggggaagagga atg-3'; CDK6 forward, 5'-tgcacagtgtcacgaacaga-3' and reverse, 5'-acctcggagaagctgaaaca-3'; cyclin D1 (CCND1) forward, 5'-ctgc gaagtggaaaccatc-3' and reverse, 5'-ttgaagtaggacaccgaggg-3'; CASP 8 forward, 5'-gatgacatgaacctgctgga-3' and reverse, 5'-cag gctcttgttgatttggg-3'; $M Y C$ forward, 5'-aggagaatgtcaagaggcga-3' and reverse, 5'-ggcctttcattgtttcca-3'; catenin $\beta 1$ (CTNNB1) forward, 5'-gctgggaccttgcataacctt-3' and reverse, 5'-atttcac cagggcaggaatg-3'; RB transcriptional corepressor 1 (RB1) forward, 5'-tgtcagagagagagcttggt-3' and reverse, 5'-ctcatctaggtcaactgctgc-3'; and transforming growth factor $\beta 1$ (TGFB1) forward, 5'-actgcg gatctctgtgtcattg-3' and reverse, 5'-acagtagtgttcccactggtc- 3 '. The $\Delta \Delta \mathrm{Cq}$ values of gene expression corresponding to the amplified mRNAs from each sample were calculated by normalizing the values to the internal control $(A C T B)$. The fold-change in expression levels was calculated using the $2^{-\Delta \Delta \mathrm{Cq}}$ method (27). All experiments were performed in triplicate.

Bioinformatic analysis of gene expression data. Bioinformatic analysis was performed to estimate the levels of gene expression for the U-87 MG and K562 cell lines employed throughout this study to assess the cytotoxicity behavior of VDS58. In detail, processed gene expression values [transcript per million reads (TPM)] resulting from the analysis of RNA-Seq data obtained from the ENCODE project (28) were downloaded from the Gene Expression Omnibus repository for untreated samples of U-87 (GSE90176) and K562 (GSE78561) cell lines. Spike-in controls and genes with TPM values equal to zero were removed from the data, and the means of the TPM expression values for each gene were then calculated. Next, for each cell line, the mean TPM values were processed via logarithm $(\log 2)$ transformation and normalized to z-scores. The density plots of the z-score gene expression values obtained for each cell line exhibited a great degree of similarity (data not shown). Using the z-scores for gene expression in U-87 

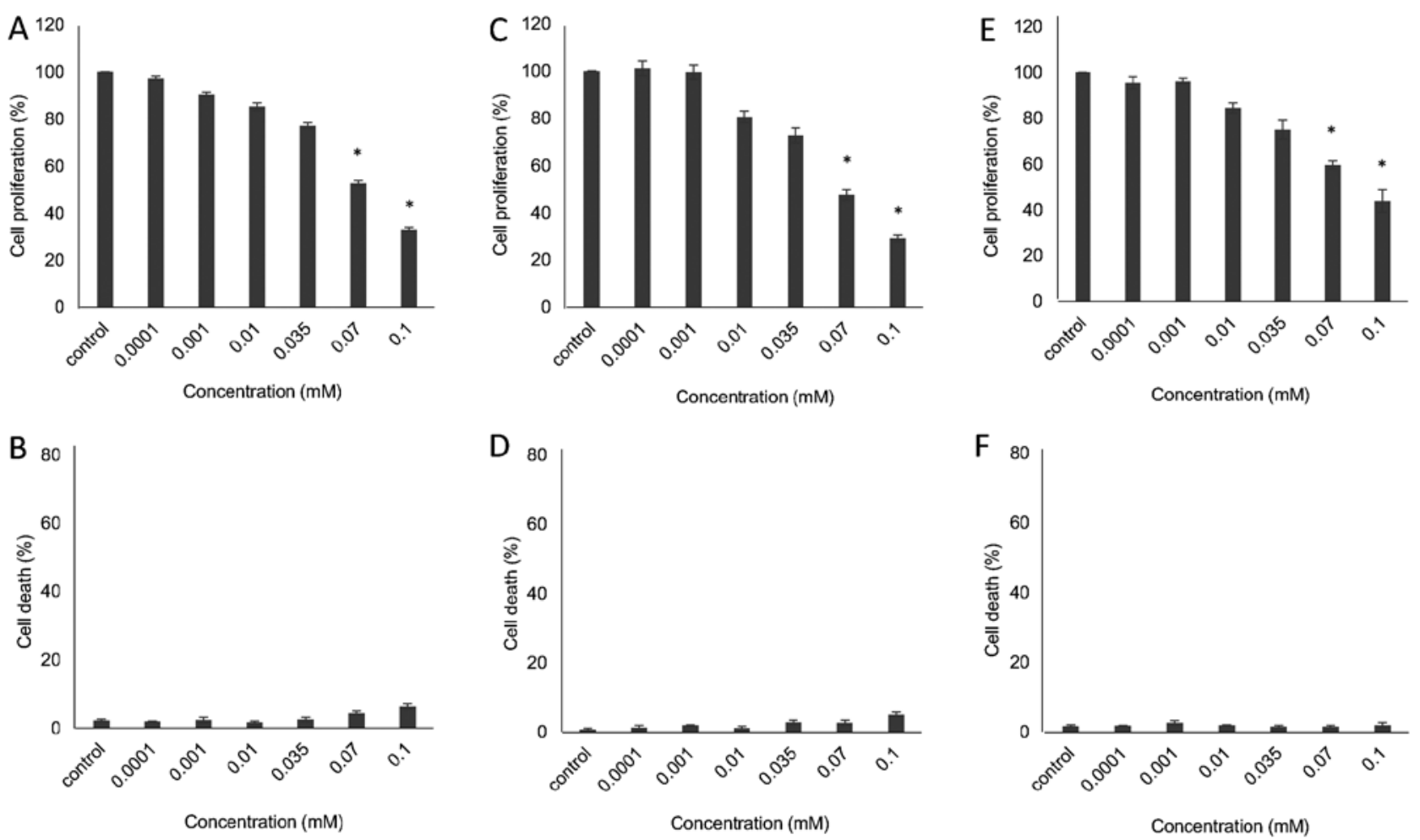

Figure 2. Assessment of cell proliferation and apoptosis in human attached cell cultures. (A, C and E) The cellular proliferation and (B, D and F) the proportion of dead cells in cultures of (A and B) glioblastoma U-87 MG, (C and D) breast carcinoma MCF-7 and (E and F) normal lung embryonic MRC-5 cells exposed to various concentrations of VDS58 for $48 \mathrm{~h}$. The values shown represent the mean \pm standard deviation of two independent experiments ( $\mathrm{n}=4$; " $\mathrm{P}<0.05 \mathrm{vs}$. control).

MG and K562 cell lines and the Pathview R package (29), visualizations were created for: i) The Homo sapiens pathway of the cell cycle (hsa04110) using information from the Kyoto Encyclopedia of Genes and Genomes database (30-32); and ii) the expression of the genes that constitute this pathway.

Statistical analysis. All data represent at least 2 independent biological experiments and the data are expressed as the mean \pm standard deviation. Comparisons were made using two-way repeated measures analysis of variance, followed by Dunnett's test. All statistical analyses were performed using GraphPad Prism 6.0 (GraphPad Software, Inc. (La Jolla, CA, USA). $\mathrm{P}<0.05$ was used to indicate a statistically significant difference.

\section{Results}

Preliminary pharmacological evaluation of natural sesquiterpenoids and analogues. The preliminary pharmacological evaluation of the obtained structural sesquiterpene derivatives shown in Fig. 1, including EA910a, EA910b, zedoarol, gweicurculactone, VDS71, VDS58, furanogermenone and EA1184, was performed in human glioblastoma U-87 MG cells by assessing their cytotoxicity profiles. The cultures were exposed to different concentrations $(0.0001-0.1 \mathrm{mM}$; $10^{-7}-10^{-4} \mathrm{M}$ ) of these compounds; cell proliferation and death were evaluated after $48 \mathrm{~h}$ of treatment. A small proportion of dead cells was observed in culture following treatment with all analogs (data not shown). Moreover, the majority of the synthetic sesquiterpene derivatives exhibited no substantial cytotoxicity based on their concentration-dependent inhibitory effects on the proliferation of U-87 MG cells; their $\mathrm{IC}_{50}$ values were $>10^{-4} \mathrm{M}$ (data not shown). Notably, however, sesquiterpene VDS58 exhibited increased cytotoxicity in a concentrationdependent manner. The proliferation of U-87 MG cells was decreased $\sim 70 \%$ following $48 \mathrm{~h}$ of exposure to VDS58 at $1 \times 10^{-4} \mathrm{M}$, compared with untreated cells (Fig. 2A and B). The latter prompted further analysis of the behavior of VDS58 in cell cultures.

Assessment of VDS58 cytotoxicity profile in various human monolayer and suspension cell cultures. The initial VDS58-induced anti-proliferative activity exhibited by U-87 MG cells prompted the further investigation of its cytotoxicity profile in various cell lines (MCF-7, MRC-5, K562 and MEL-745). These cultures were exposed to increasing concentrations of VDS58 $\left(10^{-7}-10^{-4} \mathrm{M}\right)$ for $48 \mathrm{~h}$. As shown in Figs. 2 and 3, VDS58 reduced cellular proliferation of all cell lines in a concentration-dependent manner; and cells were grown either as attached monolayers (U-87 MG, MCF-7 and MRC-5) or as suspension (K562 and MEL-745) cultures. The estimated $\mathrm{IC}_{50}$ values of VDS58 varied between the cell lines: $7 \times 10^{-5} \mathrm{M}$ for U-87 MG; $6.9 \times 10^{-5} \mathrm{M}$ for MCF-7; $9.2 \times 10^{-5} \mathrm{M}$ for MRC-5; $4.2 \times 10^{-5} \mathrm{M}$ for K562; and $2.9 \times 10^{-5} \mathrm{M}$ for MEL-745 (Table I). Notably, however, only in suspension, erythroleukemia cultures (K562 and MEL-745 cells) showed an increase in the proportion of dead cells, reaching $\sim 80 \%$ at higher concentrations $\left(1 \times 10^{-4} \mathrm{M}\right.$ for K562, Fig. 3B; $>7 \times 10^{-5} \mathrm{M}$ for MEL-745, Fig. 3D). Moreover, specific morphological changes have been recorded in the VDS58-treated cell cultures. As shown in Fig. 4, the treated U-87 MG cells lost their epithelial morphology and adherence properties. MRC-5 

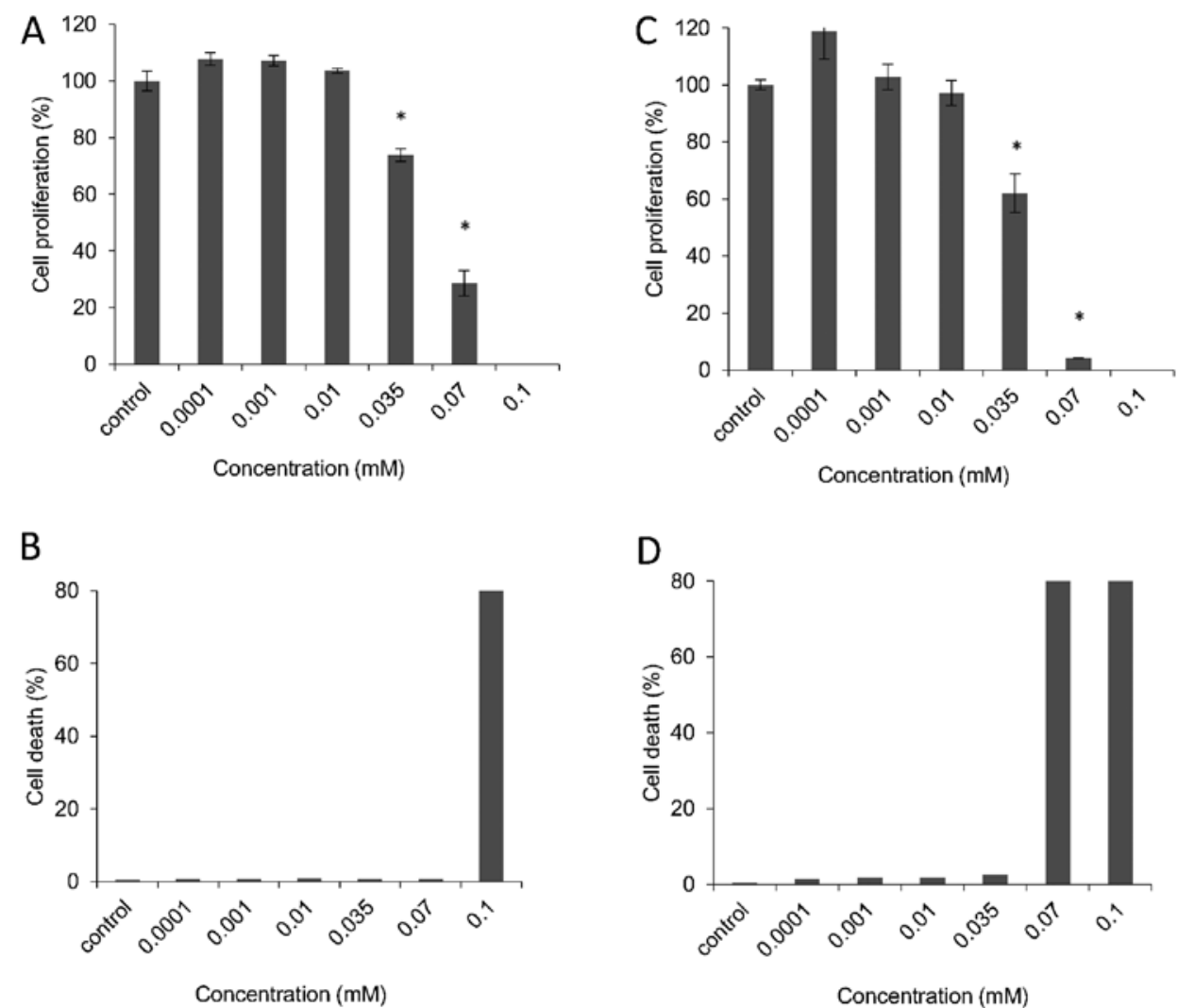

Figure 3. Assessment of cell proliferation and apoptosis in suspension cell cultures. (A and B) Human erythroleukemia K562 and (C and D) mouse erythroleukemia MEL-745 cells were incubated in culture with various concentrations of VDS58 for $48 \mathrm{~h}$. Subsequently, (A and C) cellular proliferation and (B and D) the proportion of dead cells were estimated. The values shown represent the mean \pm standard deviation of two independent experiments $\left(\mathrm{n}=4\right.$; ${ }^{*} \mathrm{P}<0.05$ vs. control).
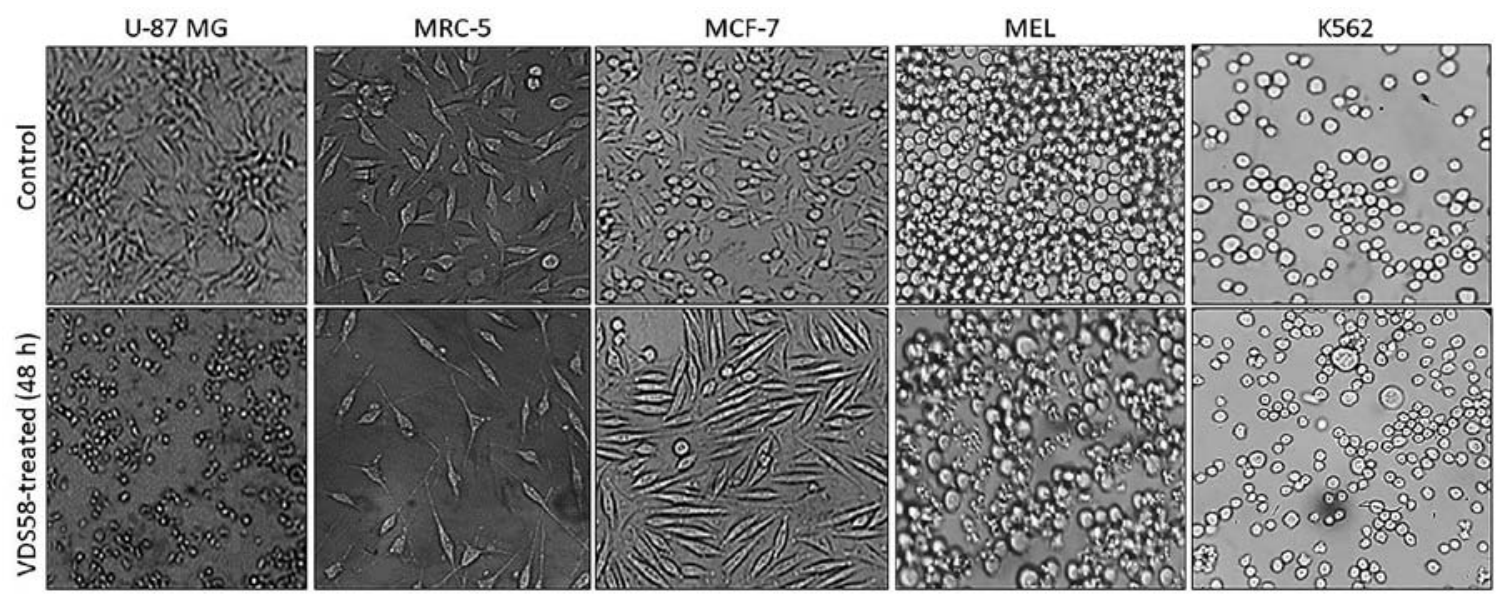

Figure 4. Morphological changes of VDS58-treated cell cultures. Malignant U-87 MG, MCF-7, K562 and MEL-745 cells, as well as normal MRC-5 cells, were exposed to VDS58 at the half maximal inhibitory concentration for each individual cell line (Table I) for $48 \mathrm{~h}$. The morphology of cells is shown in the images taken using an inverse light microscope (x40 magnification).

cultures exhibited a spindle-like phenotype and MCF-7 cells obtained a fibroblastic-mesenchymal type shape, whereas in suspension, K562 and MEL-745 cultures possessed large cells, an indicator of cytotoxicity. Thus, contrary to the limited effects observed for the other sesquiterpene molecules (EA910a, EA910b, zedoarol, gweicurculactone, VDS71, furanogermenone and EA1184), the VDS58 analog exhibited a notable concentration-dependent cytotoxicity profile, which was accompanied by cellular morphological changes in the malignant and normal (MRC-5) cells.
Kinetic analysis of cell proliferation of human cell lines exposed to VDS58. To better characterize the cytotoxic effects of VDS58, the cell cultures were treated continuously with the corresponding $\mathrm{IC}_{50}$ of VDS58 for 4-5 days. As shown in Fig. 5, U-87 MG cells exposed to the $\mathrm{IC}_{50}$ of VDS58 grew at slower rates in culture; however, after 48-72 $\mathrm{h}$, the cell numbers were comparable to those of the control cells, with no notable changes in the proportion of dead cells (Fig. 5A and B). Moreover, MCF-7 cells treated with the $\mathrm{IC}_{50}$ of VDS58 showed similar behaviors, 

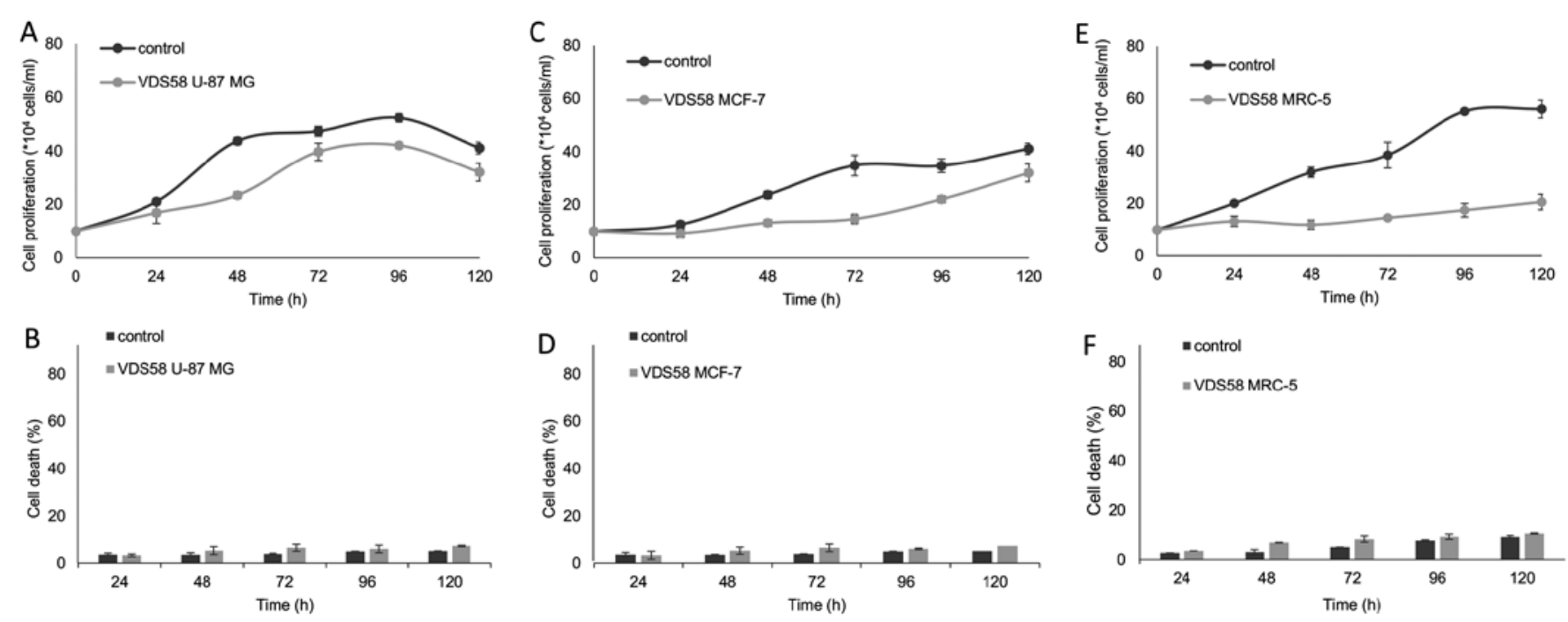

Figure 5. Kinetic analysis of cell proliferation and apoptosis in human attached cell cultures. Malignant (A and B) U-87 MG and (C and D) MCF-7 cells, and (E and F) normal MRC-5 cells were incubated with the half maximal inhibitory concentration of VDS58, as shown in Table I for each cell line. At the time intervals indicated in the panels (24-120 h), (A, C and E) the cell proliferation and (B, D and F) the proportion of dead cells were measured. The values shown represent the mean \pm standard deviation of two independent experiments $(n=4)$.
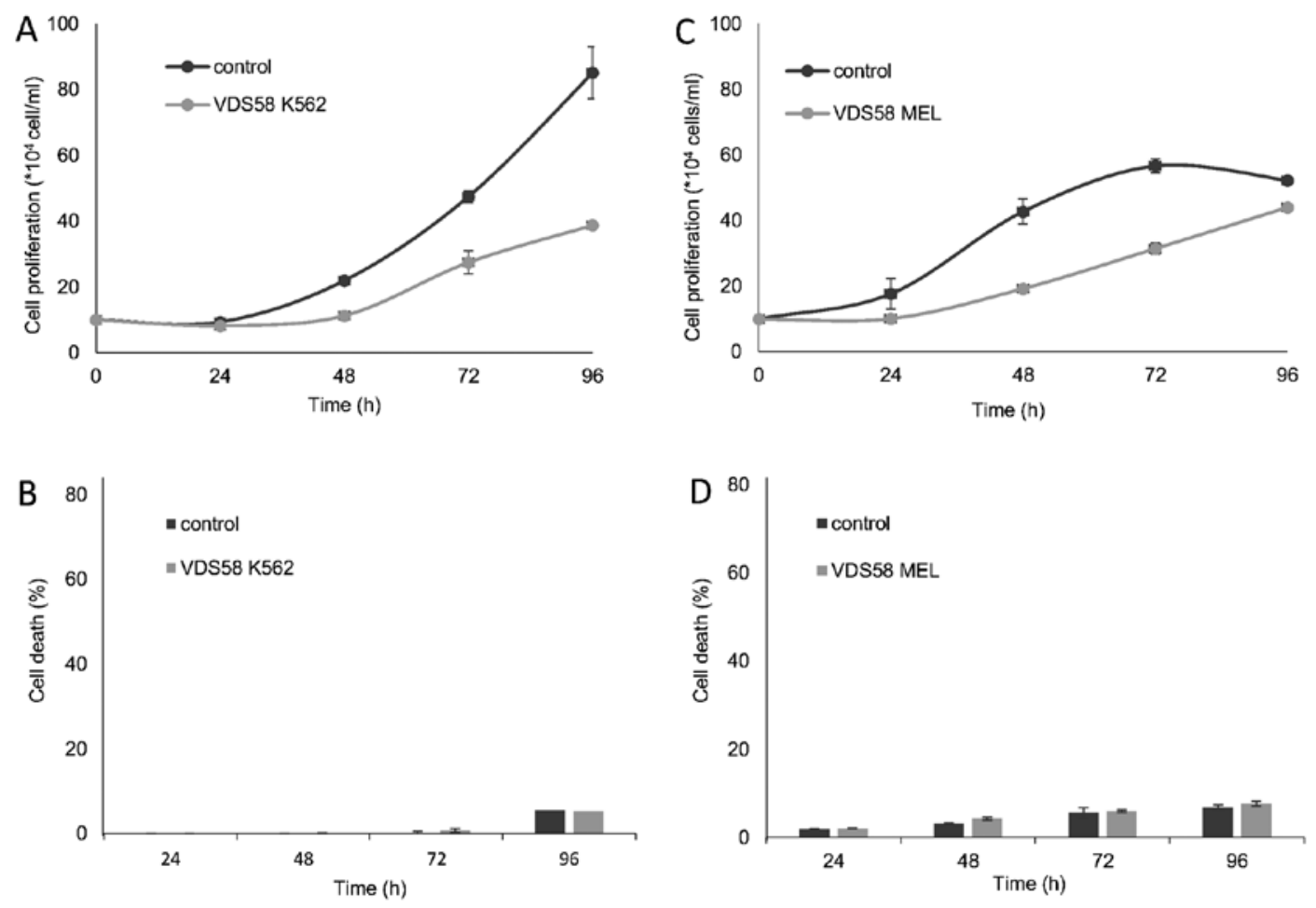

Figure 6. Kinetic analysis of cell proliferation and apoptosis in suspension cell cultures. (A and B) Erythroleukemia human K562 and (C and D) mouse MEL-745 cells were incubated with the half maximal inhibitory concentration of VDS58, as shown in Table I for each cell line. At the time intervals indicated $(24-120 \mathrm{~h}),(\mathrm{A}$ and $\mathrm{C})$ the cell proliferation and (B and D) the proportion of dead cells were assessed. The values shown represent the mean \pm standard deviation of two independent experiments $(n=4)$.

although a treatment time of $96-120 \mathrm{~h}$ was required to obtain cell numbers comparable with those of the untreated cells (Fig. 5C and D). Notably, normal MRC-5 cells incubated with the $\mathrm{IC}_{50}$ of VDS58 did not proliferate notably, even after $120 \mathrm{~h}$ of treatment (Fig. 5E and F). The erythroleukemia K562 and MEL-745 cell lines, which were exposed to the corresponding $\mathrm{IC}_{50}$ of VDS58, exhibited slow proliferation rates compared with those of the controls (Fig. 6).
Notably, in the attached VDS58-treated cultures, particularly in the malignant U-87 MG and MCF-7 cells, the cells survived and exhibited high proliferation rates; an effect that was more prominent in the U-87 MG cells compared with that observed in the normal attached MRC-5 cells (Fig. 5). Thus, to gain more insight into the cellular effects of VDS58, particularly in glioblastoma U-87 MG and normal MRC-5 cells, a complementary set-up of kinetic experiments was 

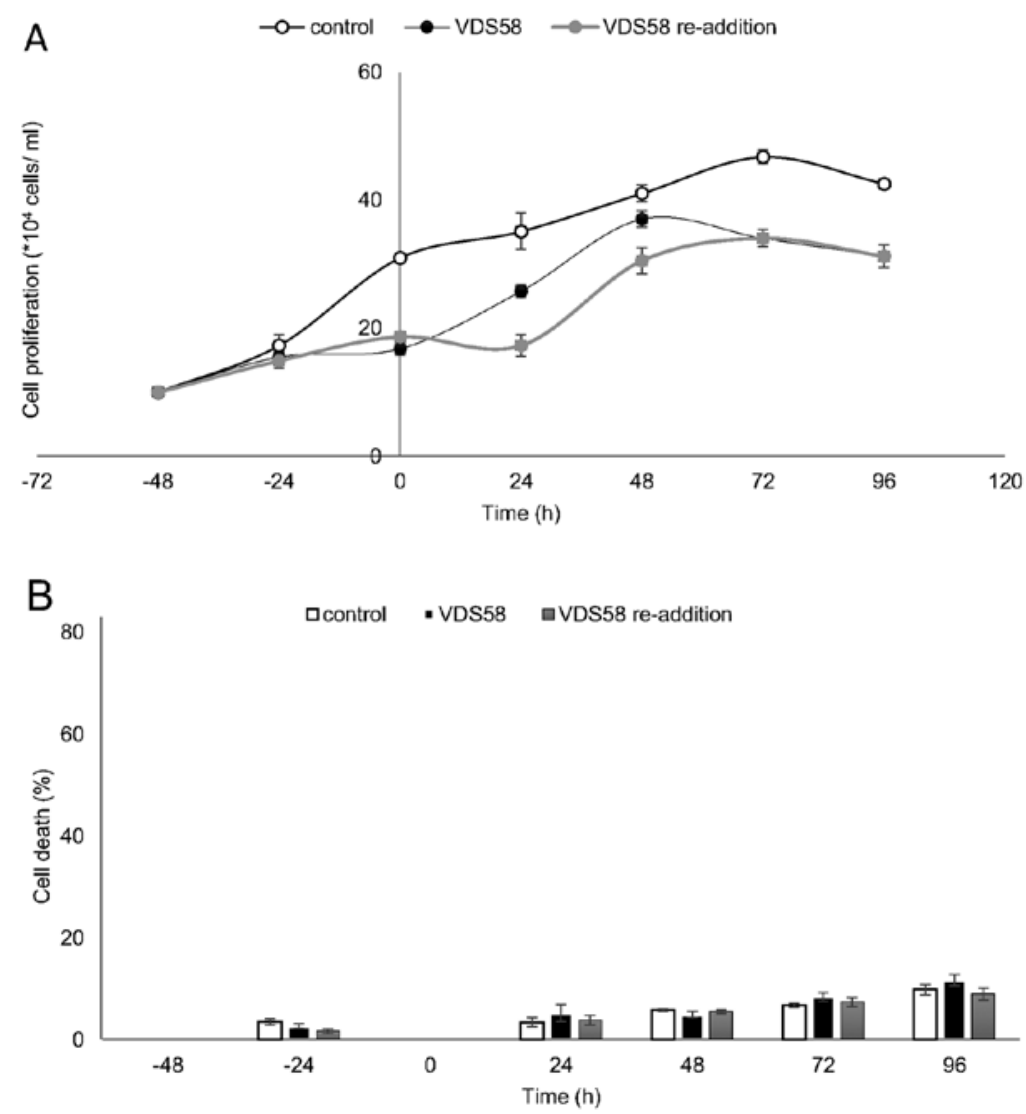

Figure 7. Assessment of the cell proliferation potential of U-87MG cell cultures following re-exposure to VDS58. (A) U-87MG cells grown in culture were continuously treated with $7 \times 10^{-5} \mathrm{M}\left(\mathrm{IC}_{50}\right.$ concentration) of VDS58 for $48 \mathrm{~h} \mathrm{(-24}$ and $-48 \mathrm{~h}$ pretreatment). After this time, the cells were washed out twice with 1X PBS. Next, fresh medium was added to the culture containing the same amount as the initial treatment $\left(7 \times 10^{-5} \mathrm{M}\right.$; IC s0 $_{0}$ concentration) of VDS58 (time 0$)$. The cells were then further allowed to grow in culture for 4 days $(96 \mathrm{~h}$ ). (A) Cell proliferation and (B) the proportion of dead cells were assessed. The data shown indicates a representative experiment where three independent measurements were used to calculate the mean. A biological replication of this experiment was performed twice with similar results. $\mathrm{IC}_{50}$, half maximal inhibitory concentration.

Table I. $\mathrm{IC}_{50}$ values of VDS58 in various cell lines.

\begin{tabular}{lc}
\hline Cell line & $\mathrm{IC}_{50}(\mathrm{M})$ \\
\hline U-87 MG & $7 \times 10^{-5}$ \\
MCF-7 & $6.9 \times 10^{-5}$ \\
MRC-5 & $9.2 \times 10^{-5}$ \\
K562 & $4.2 \times 10^{-5}$ \\
MEL & $2.9 \times 10^{-5}$
\end{tabular}

$\mathrm{IC}_{50}$, half maximal inhibitory concentration.

designed. For U-87 MG cells, the question to be addressed in these experiments was whether the cells were able to avoid the effects exerted by VDS58 conveyed by its intracellular metabolism leading to its cellular inactivity. For MRC-5, the current study investigated whether the cells regained their proliferation capacity following the removal of VDS58 from the culture. To this end, these cultures were initially exposed for $48 \mathrm{~h}$ to the corresponding $\mathrm{IC}_{50}$ of VDS58 for each culture

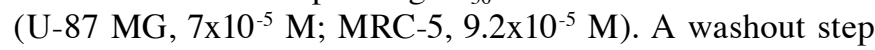
was subsequently introduced, (referred to as time-point ' 0 '), followed by the addition of fresh medium containing VDS58 $\left(7 \times 10^{-5} \mathrm{M}\right)$ for U-87 MG cells, whereas for MRC-5 cells, the culture medium was free of VDS58. In all cases, the control cultures were included in the experimental design to facilitate the interpretation of the results. The results of the current study showed that malignant U-87 MG cells have the ability to regain their proliferative potential subsequent to the initial pretreatment (Fig. 7A). At 48-72 $\mathrm{h}$ after the re-addition of VDS58, the cell number was similar to that of the culture continuously treated with VDS58, while the untreated control exhibited a higher cell accumulation rate (Fig. 7). These data suggest that the observed behavior of U-87 MG cells to escape and overcome the proliferation inhibitory effects of VDS58 may be attributed to an intrinsic capacity of U-87 MG cells rather than the intracellular metabolism of VDS58. The results of a typical washout experiment for MRC-5 cells pretreated for either 24 or $48 \mathrm{~h}$ with VDS58 are shown in Fig. 8. The initial inhibition of cell proliferation, as expected with exposure to VDS58 (Fig. 5E), was followed by a proliferative phase after the replenishment of cultures and transfer of cells into VDS58-free fresh medium (Fig. 8A). This implies that the intracellular actions of VDS58 may not cause any permanent harmful effects on the proliferation of normal MRC-5 cells; thus, cells are able to grow again, soon after the removal of VDS58 from the culture. Such behavior suggests the capability of MRC-5 cells to regain their potential to proliferate even subsequent to exposure to VDS58. Alternatively, it indicates the presence of inherent molecular machinery within MRC-5 

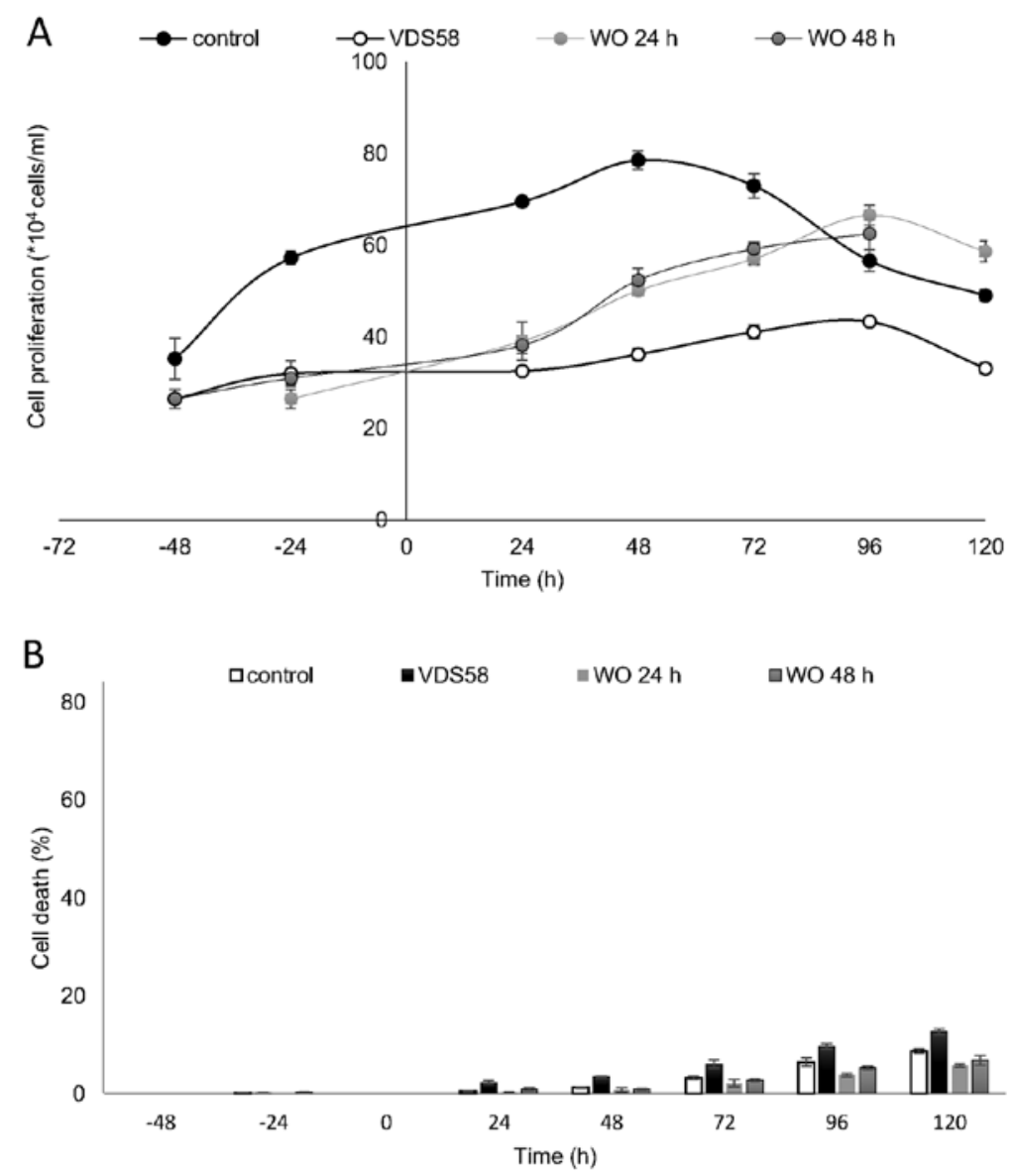

Figure 8. Assessment of cell proliferation potential of MRC-5 cells following pretreatment with VDS58. (A) Normal human MRC-5 cells grown in culture were initially treated with VDS58 $\left(9.2 \times 10^{-5} \mathrm{M}\right.$; half maximal inhibitory concentration for this cell line, as shown in Table I) at time intervals (-24 and $-48 \mathrm{~h}$, pretreatment). Afterwards, cells were washed out twice with 1X PBS (time 0), prior to fresh medium without VDS58 being added to the culture. Thus, the cells were permitted to grow in the absence of VDS58 for $120 \mathrm{~h}$. (A) Cell proliferation and (B) the proportions of dead cells were assessed. The data shown indicate a representative experiment where three independent measurements were used to calculate the mean. A biological replication of this experiment was performed twice with similar results.

cells, enabling them to regain their full proliferation potential, as VDS58-pretreated cells grow after the removal of the agent and attain cell numbers comparable with that of the control culture.

Gene expression profiling of human cell lines incubated with VDS58. Numerous compounds exert their cytotoxic effects by deregulating the cell cycle or by inducing apoptotic signaling pathways. The kinetic analysis of cell proliferation prompted the further elucidation of the molecular mechanisms underlying the cellular responses in VDS58-treated cultures via RT-qPCR gene expression analysis in the present study. The assessment focused on 16 genes associated with the cell cycle, apoptosis and/or senescence (Fig. 9). U-87 MG cells continuously treated with the $\mathrm{IC}_{50}$ concentration of VDS58 exhibited a substantial increase in gene expression levels of $C D K N 1$ ( 12-fold), CASP9 ( 7-fold), BCL2 ( 4-fold), TGFB1 ( 3.5-fold) and CTNNB1 ( 2-fold) $(\mathrm{P}<0.05)$ (Fig. 9A). However, the significantly upregulated expression of these genes returned to basal levels after $48 \mathrm{~h}$ of treatment, excluding that of TGFBl and $C T N N B 1$, in which upregulated levels were maintained even after $72 \mathrm{~h}$. Such data indicate the transient induction of the $C D K N 1$ signaling pathway and the ability of U-87 MG cultures to overcome the effects of VDS58. Notably, the re-addition of
VDS58 to the U-87 MG cultures after an initial $48 \mathrm{~h}$ exposure caused a more profound activation of all genes, excluding $B A X, C A S P 8$ and $R B 1$ (Fig. 9B). Highly increased expression levels of $B A D$ ( 13-fold), CASP9 ( 12-fold), CASP3 ( 9-fold), TP53 ( 8-fold), CDK6 ( 6-fold) and CDKN1 ( 5-fold), as well as $M Y C, C C N D 1, C D K 2$ and $C D K 4$ ( $\sim$-fold), and TGFB1 $(\sim 2.5$-fold $)$, were observed $(\mathrm{P}<0.05)$. In the latter case, the expression levels of all genes returned to their initial levels, excluding those for MYC and TGFBl following $48 \mathrm{~h}$ of cell re-exposure to VDS58. By contrast, the gene expression profiles of VDS58-treated K562 cells revealed no notable alteration in gene expression levels, since only TGFB1 ( 3-fold), CTNNB1 ( 2-fold), CASP3 ( 2-fold) and BAX ( 1.5-fold) showed a time-dependent increase for at least $48 \mathrm{~h}(\mathrm{P}<0.05)$ (Fig. 10). Similarly, RT-qPCR analysis was performed with MCF-7 and MRC-5 cultures exposed to VDS58; however, no alterations in gene expression levels were recorded between treated and untreated cells (data not shown). Notably, within the panel of genes analyzed in MRC-5 cells, only $C D K 2, C D K 6, B A D$, $B A X$ and $B C L 2$ appeared to have been amplified by RT-qPCR, as also reported in our recent study (22).

Bioinformatic analysis of gene expression data to assess the molecular heterogeneity underlying the response of U-87 MG 

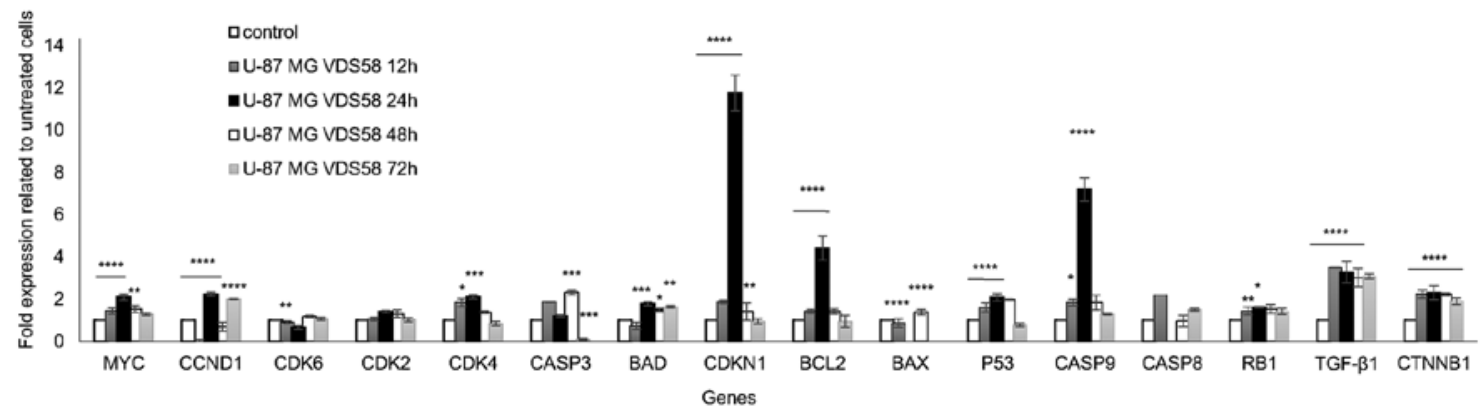

B

U-87 MG after re-addition of VDS58

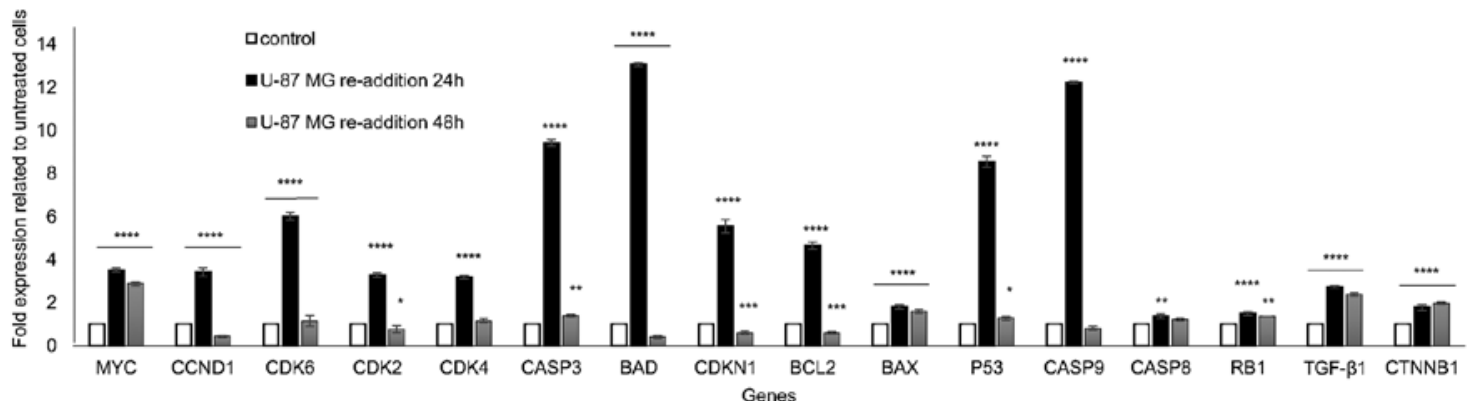

Figure 9. Gene expression profiling by reverse transcription-quantitative polymerase chain reaction analysis of U-87 MG cells exposed to VDS58. (A) Expression profiles of proliferation- and apoptosis-related genes of cytoplasmic RNA isolated from U-87 MG cells continuously treated with VDS58 (7x10 ${ }^{-5} \mathrm{M}$; $\mathrm{IC}_{50}$ concentration) for 12, 24, 48 and $72 \mathrm{~h}$. (B) Gene expression profiles of U-87 MG cells initially pretreated with VDS58 for $48 \mathrm{~h}$, prior to the replenishment of cells and the addition of fresh medium in culture containing VDS58 $\left(7 \times 10^{-5} \mathrm{M} ; \mathrm{IC}_{50}\right.$ concentration), as shown in Fig. 7. The data shown indicate a representative experiment where three independent measurements were used to calculate the mean \pm standard deviation $(\mathrm{n}=4)$. ${ }^{*} \mathrm{P}<0.05,{ }^{* * *} \mathrm{P}<0.01,{ }^{* * * *} \mathrm{P}<0.001$ and ${ }^{* * * *} \mathrm{P}<0.0001$ compared with the control. A biological replication of this experiment was performed twice with similar results. $\mathrm{IC}_{50}$, half maximal inhibitory concentration; MYC, MYC proto-oncogene bHLH transcription factor; CDK, cyclin-dependent kinase; CASP, caspase; BAD, BCL2-associated agonist of cell death; CDKN1, cyclin-dependent kinase inhibitor 1A; BCL2, BCL2-associated agonist of cell death; BAX, BCL2-associated X apoptosis regulator; TP53, tumor protein 53 ; RB1, RB transcriptional corepressor 1 ; TGF- $\beta 1$, transforming growth factor- $\beta 1$; CTNNB1, catenin $\beta 1$.

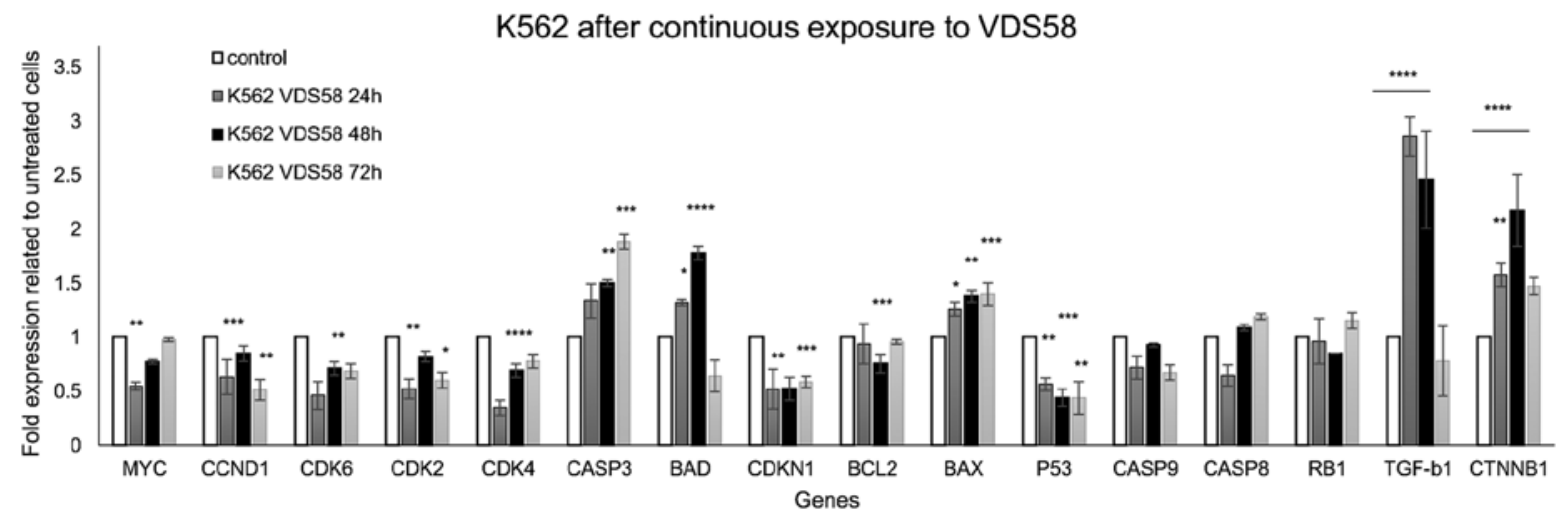

Figure 10. Gene expression profiling by RT-qPCR. analysis of K562 cells exposed to VDS58. K562 cells were continuously treated with VDS58 (4.2x10-5 M; $\mathrm{IC}_{50}$ concentration; Table I) for 24, 48 and $72 \mathrm{~h}$. The RT-qPCR analysis of isolated cytoplasmic RNA was performed as shown in Fig. 9. The data shown indicate a representative experiment where three independent measurements were used to calculate the mean \pm standard deviation $(n=4)$. ${ }^{*} \mathrm{P}<0.05,{ }^{* *} \mathrm{P}<0.01$, ${ }^{* * * *} \mathrm{P}<0.001$ and ${ }^{* * * *} \mathrm{P}<0.0001$ compared with the control. A biological replication of this experiment was performed twice with similar results. RT-qPCR, reverse transcription-quantitative polymerase chain reaction; MYC, MYC proto-oncogene bHLH transcription factor; CDK, cyclin-dependent kinase; CASP, caspase; BAD, BCL2-associated agonist of cell death; CDKN1, cyclin-dependent kinase inhibitor 1A; BCL2, BCL2-associated agonist of cell death; BAX, BCL2associated $\mathrm{X}$ apoptosis regulator; TP53, tumor protein 53 ; RB1, RB transcriptional corepressor 1 ; TGF- $\beta 1$, transforming growth factor- $\beta 1$; CTNNB1, catenin $\beta 1$.

and $K 562$ cells to VDS58 treatment. The diverse cytotoxic responses observed upon the exposure of U-87 MG and K562 cells to VDS58 were accompanied by a differential gene expression profile in the same cultures (Figs. 9 and 10). To improve our understanding of such cellular behavior, a bioinformatic pathway analysis of whole genome RNA-Seq expression data from the ENCODE project available for parental U-87 MG and K562 cells was performed, focusing on genes involved in the cell cycle, senescence and/or apoptosis signaling pathways (Fig. 11). Analysis of the associations between gene expression levels 
A

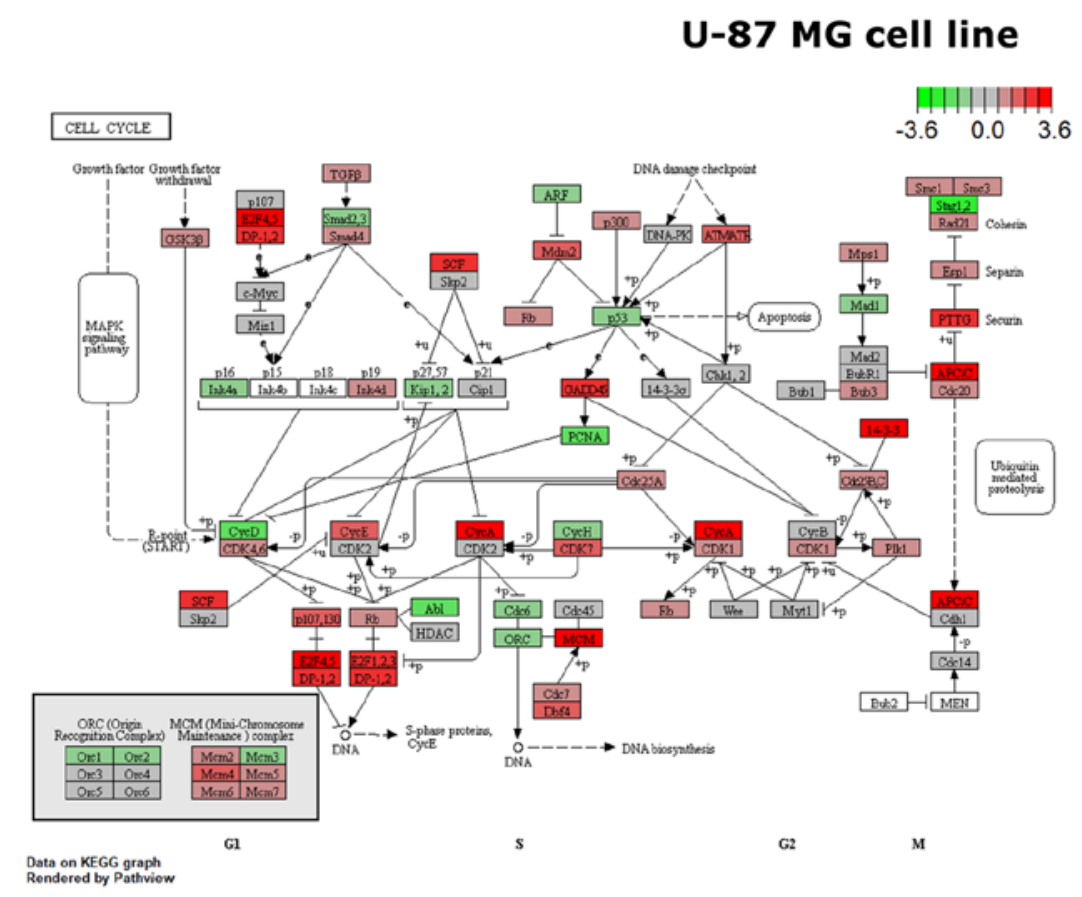

D

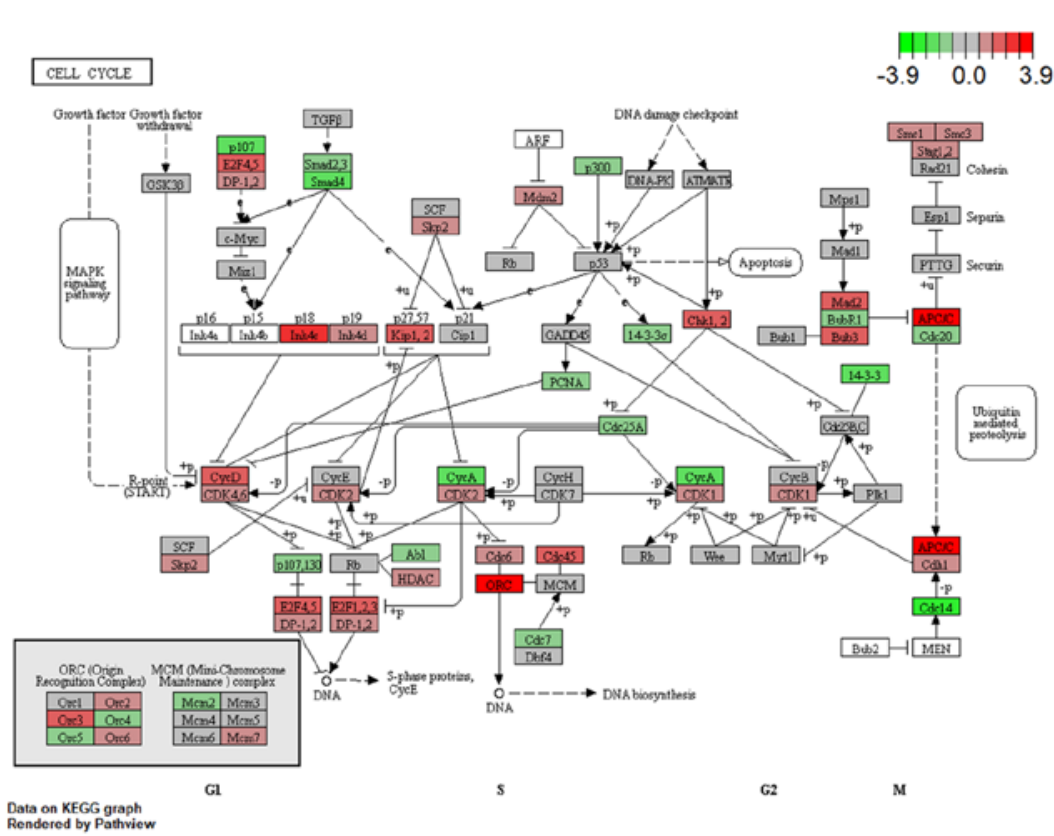

B<smiles>OCC1CCCC1</smiles>

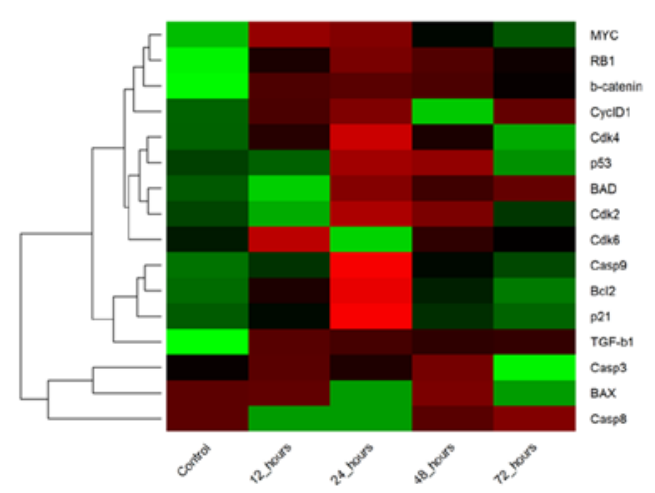

C

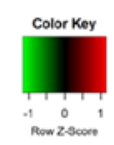

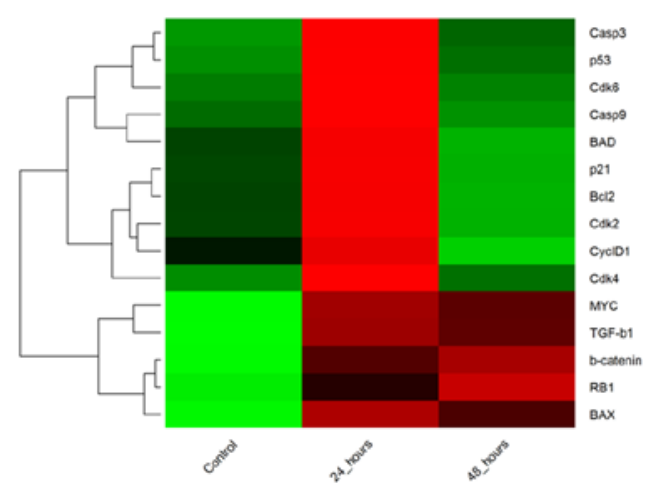

E
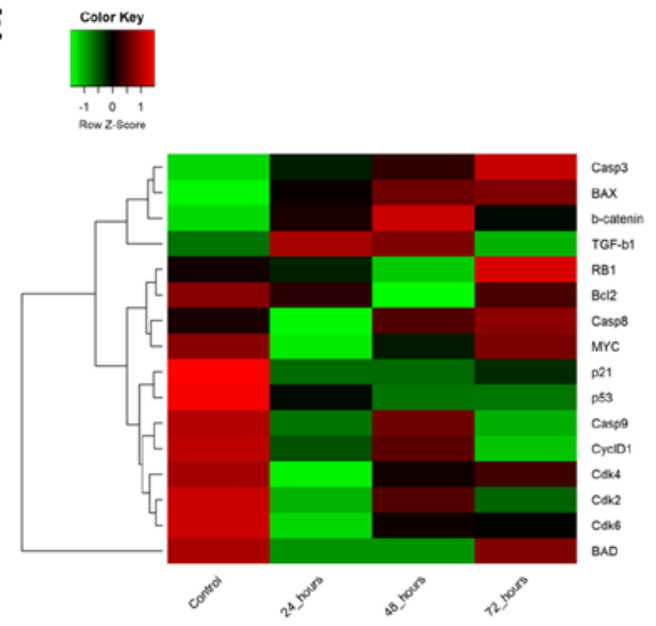

Figure 11. Cell cycle pathway visualization using RNA-Seq ENCODE data and heatmaps of expression for selected genes of U-87 MG and K562 cells exposed to VDS58 as analyzed by RT-qPCR. (A and D) Expression of genes that participate in the cell cycle pathway, as profiled by RNA-sequencing for untreated (A) U-87 MG and (D) K562 cell lines (data from the ENCODE project). Transcript per million reads values for all genes expressed in each cell line were normalized to z-score, and genes associated with the cell cycle were extracted from the Kyoto Encyclopedia of Genes and Genomes database (29-31) and rendered in graphs using Pathview (28). (B and C) The heatmaps show the expression of selected genes participating in cellular senescence, apoptosis and the cell cycle in the U-87 MG cell line. U-87 MG cells were (B) continuously exposed to the substance for 0 (control), 12, 24, 48 and $72 \mathrm{~h}$, and (C) continuously exposed to the substance for $48 \mathrm{~h}$ (control) following re-addition at 24 and $48 \mathrm{~h}$. (E) The heatmaps show the expression of selected genes involved in cellular senescence, apoptosis and the cell cycle in K562 cells. K562 cells were continuously exposed to VDS58 for 0 (control), 24, 48 and $72 \mathrm{~h}$. Gene expression values for all heatmaps were measured using SYBR RT-qPCR and normalized to z-score values for each gene. RT-qPCR, reverse transcription-quantitative polymerase chain reaction. 
associated with these aforementioned signaling pathways in the two parental cell lines unveiled substantial differences (Fig. 11A and D). Notably, the comparison between the two cell lines showed that crucial genes involved in the cell cycle pathway, including TGFB1, MYC, TP53, RB1, CDKN2A, $C D K N 1 B, C D K N 1, C D K 2$ and $C C N D 1$, exhibited greater variation in expression levels. Consequently, this existing variability in cell cycle gene expression profiles could contribute toward the notable diversity in the cytotoxic response of cultures to VDS58 treatment. To further analyze the gene expression profile and detect the molecular profiles in VDS58-treated cell cultures over time, heatmaps were created from the generated RT-qPCR data (Figs. 9 and 10), and are presented in Fig. 11B, C and E. Evidently, the existing variability in gene expression levels of parental U-87 MG and K562 cells from the RNA-Seq data of the ENCODE project was further confirmed in the RT-qPCR data by comparing control cultures (Fig. 11B vs. E). Moreover, the kinetic analysis of the gene expression levels analyzed following VDS58 exposure exhibited a different pattern during the 24-72 $\mathrm{h}$ course of investigation. This may contribute toward the observed differential pharmacological response observed in the two cell lines. The re-addition of VDS58 to U-87 MG cultures, after initial exposure to the same agent, allowed cells to present a clear molecular profile, in which two main groups of genes could be identified. In the first group, the expression of the BAX, RB1, CTNNB1, TGFB1 and MYC genes was increased after $24 \mathrm{~h}$ following the re-addition of VDS58 and maintained at this level afterwards. In the second group representing the rest of the genes under investigation, a transient 24-h activation of expression was observed, which after $48 \mathrm{~h}$ returned to the initial level reaching that of control untreated cultures (Fig. 11C).

\section{Discussion}

Tumor cell heterogeneity and genomic instability are factors that contribute toward the poor outcomes of cancer therapy in clinical practice. Moreover, the development of drug resistance represents a hallmark of malignant cells to escape the effects of anticancer agents. An improved understanding of the molecular mechanisms underlying the variable response of cancer cells to environmental stimuli and therapeutic agents is of high demand in the development of novel anticancer drugs $(6,33)$. To this end, the selective cytotoxicity observed for the SL analogs, including artemisin, thapsigargin and parthenolide, has led to further pharmacological investigation through their evaluation in clinical trials; however, specific pharmacokinetic issues have been raised (15-17). For example, parthenolide presents poor bioavailability and thus efforts have been made to produce molecules with enhanced solubility and membrane permeability (9,34-36). Moreover, the potent ability of parthenolide to inhibit $\mathrm{NF}-\kappa \mathrm{B}$ is recognized as one of the potential factors for its selective action for targeting tumor and cancer stem cells. Parthenolide was found to directly modify the p65 subunit of NF- $\kappa \beta$ and suppress the activity of the upstream I $\kappa \mathrm{B}$ kinase complex leading to stabilization of the $\mathrm{NF}-\kappa \mathrm{B}$ inhibitors, I $\mathrm{B} \mathrm{B} \alpha$ and $\mathrm{I} \kappa \mathrm{B} \beta$ (37-39).

Notably, the total synthesis of sesquiterpenes and SLs has led to intense research efforts for decades; however, only a few unified synthetic protocols have been published to analyze the diverse carbocyclic complexity presented by the sesquiterpenoid family $(20,21,40,41)$. Furthermore, despite extensive studies on the chemical synthesis and biology of 6,12-SLs, the isomeric 8,12-SLs, comprising almost half of the natural substances, have received relatively limited attention in the pharmacological field, restricting the identification of the pharmacological potential of this family of compounds (42). Thus, efforts to improve our understanding of the molecular mechanisms underlying the effects of SLs in cancer cells are urgently required to ensure the clinical exploitation and application of these compounds as potential anticancer therapeutic agents.

The CDK inhibitor CDKN1 promotes cell cycle arrest in response to a number of stimuli, including activation of TP53 and TGFB1, and suppression of $M Y C$ (43). The knowledge accumulated thus far regarding the dysregulation of $C D K N 1$ has revealed that several important tumor suppressor and oncogenic signaling pathways may alter $C D K N 1$ expression to exert their effects on cell cycle progression, survival, senescence and apoptosis (44). Additionally, the co-operation of $C D K N 1$ with tumor suppressor molecules or conversely, the antagonism with oncogene products, leads to tumor cell regression (45). It is notable that tumor cell senescence is induced by $C D K N 1$ subsequent to restoring TP53 function or inactivating $M Y C$ in tumors with functional TP53 $(46,47)$. Moreover, the anti-proliferation activity of $T G F B 1$ on tumor cells is mediated through the activity of a repressive transcription factor complex constituting SMAD4, p107 and E2F4/5, which is mediated by the suppression of MYC (48). Consequently, $C D K N 1$ expression can promote and inhibit tumorigenic processes, depending on the existing molecular heterogeneity within various tumor cell types and microenvironments (43). Alternatively, variations in cellular response and the complexity of the molecular events that are associated with the dysregulation of CDKN1 imply that further understanding of these molecular mechanisms is required prior to the potential therapeutic roles of $C D K N 1$ being investigated for the development of novel drugs for the treatment of cancer.

The data obtained in the present study presents a solid foundation of evidence as to how the sesquiterpene derivative VDS58 exerts its differential cytotoxic effects in cancer and normal cell lines of various histopathological origins and heterogeneous gene expression profiles. Normal MRC-5 cells exhibit higher $\mathrm{IC}_{50}$ to VDS58 than U87 MG and recover their proliferation capacity in a manner dependent to the exposure period to VDS58. Moreover, the differential cytotoxicity profile observed in the cell cultures has prompted us to focus on elucidating the molecular events underlying the pharmacological response. However at this time, the high $\mathrm{IC}_{50}$ of VDS58 restricts any further consideration of in vivo studies. The unique ability of U-87 MG cells to transiently induce the expression of genes involved in the cell cycle, senescence and apoptosis imply heterogeneity at the molecular level and in the underlying signaling pathways. Indeed, this was verified by conducting a pathway bioinformatic analysis of whole genome RNA-Seq data of the ENCODE project, in which the human parental U-87 MG glioblastoma and K562 erythroleukemia cells presented a substantially marked difference in the expression levels of crucial genes governing cell cycle decisions, 
including $M Y C, T P 53, T G F B 1, C C N D 1$ and $R B 1$. Notably, in K562 cells exposed to VDS58, the expression of certain genes, mainly TGFB1 and, to a lesser extent, $C T N N B 1, B A D, B A X$ and $C A S P 3$, was induced, and activation was maintained at this level for 48-72 $\mathrm{h}$. These results further support the hypothesis that variations in the cytotoxicity observed in different cell cultures reflect the heterogeneous gene expression profiles that exist within these parental cell lines. Notably, genes such as $M Y C$ and TGFB1 in U-87 MG cells exposed to VDS58 exhibited a persistent increase in expression, while the remaining genes, including $C D K N 1, C A S P 9, B C L 2$ and $T P 53$, were only induced for $24 \mathrm{~h}$. This observation suggests that the related signaling pathways are differentially affected by the homeostatic genomic mechanisms that govern the cellular behavior following exposure to VDS58. The current study observed that U-87 MG cells were capable of recovering their proliferation rates soon after 24-48 $\mathrm{h}$ following exposure to VDS58, which coincides with the gene expression profiles. Moreover, the persistence of induced expression levels for TGFBI and $M Y C$ only could provide support for cell proliferation after the initial cell cycle arrest of cells, due to the transient increase in the expression level of $C D K N 1$. Additionally, U-87 MG and K562 cells treated with VDS58 exhibited increased TGFB1 expression levels; however, variations in their cellular proliferation responses were noticed.

The analysis of gene expression profiles by creating the corresponding heatmaps permitted the identification of heterogeneity in the expression of crucial genes and signaling pathways within the two parental cell lines. Consequently, such an approach has permitted variations in expression to be revealed within the molecular signatures of the genes analyzed. This observation could be important in understanding the molecular mechanisms that aid cancer cells in evading therapeutic interventions by overcoming proliferation restriction signals, or by developing drug resistance. The results of the current study provide new knowledge on the anticancer properties of sesquiterpene and present evidence toward understanding the mechanism of action exhibited by sesquiterpene analogs as potential antitumor drug targets. Additionally, this study further contributes to improving methodologies to develop potential candidate molecules as anticancer agents to target cell cycle signaling pathways. However, the $\mathrm{IC}_{50}$ values of the tested SLs analogs are high enough to determine a clearer picture for their cytotoxicity profile. Also, it is necessary to further clarify the precise molecular mechanisms underlying the effects of VDS58 against tumor cells prior to this agent being considered for further pharmacological evaluation and development. To this end, by synthesizing more cytotoxic SLs and applying genomics and proteomics approaches, such therapeutic possibilities will be effectively addressed.

\section{Acknowledgements}

Not applicable.

\section{Funding}

This study was funded by interdepartmental public funds of Aristotle University of Thessaloniki.

\section{Availability of data and materials}

The datasets used and/or analyzed during the current study are available from the corresponding author on reasonable request.

\section{Authors' contributions}

ALZ and VPD synthesized the sesquiterpene compounds; MGA and NFT performed cell and molecular experimental work; ISV supervised the whole study; MGA performed the statistical analysis; KAK performed the bioinformatic analysis; FMC and NG provided resources; ALZ and ISV designed the experimental methodology and analyzed the data. MGA, VPD, NFT, FMC, KAK, NG, ALZ and ISV contributed to the interpretation of the experimental data and to the writing of the manuscript.

\section{Ethics approval and consent to participate}

Not applicable.

\section{Patient consent for publication}

Not applicable.

\section{Competing interests}

The authors declare that they have no competing interests.

\section{References}

1. Shah NP, Nicoll JM, Nagar B, Gorre ME, Paquette RL, Kuriyan J and Sawyers CL: Multiple BCR-ABL kinase domain mutations confer polyclonal resistance to the tyrosine kinase inhibitor imatinib (STI571) in chronic phase and blast crisis chronic myeloid leukemia. Cancer Cell 2: 117-125, 2002.

2. Newman DJ and Cragg GM: Natural products as sources of new drugs over the 30 years from 1981 to 2010. J Nat Prod 75: 311-335, 2012.

3. Wall ME, Wani MC, Cook CE, Palmer KH, McPhail AT and Sim GA: Plant antitumor agents. I. The isolation and structure of camptothecin, a novel alkaloidal leukemia and tumor inhibitor from Camptotheca acuminata. J Am Chem Soc 88: 3888-3890, 1966.

4. Cragg GM and Newman DJ: Nature: A vital source of leads for anticancer drug development. Phytochem Rev 8: 313-331, 2009.

5. Song Y, Sun H,Zhang A, Yan G,Han Y and Wang X: Plant-derived natural products as leads to anti-cancer drugs. J Med Plant Herb Ther Res: 6-15, 2014.

6. Vizirianakis IS, Chatzopoulou M, Bonovolias ID, Nicolaou I, Demopoulos VJ and Tsiftsoglou AS: Toward the development of innovative bifunctional agents to induce differentiation and to promote apoptosis in leukemia: Clinical candidates and perspectives. J Med Chem 53: 6779-6810, 2010.

7. Tao W, Li B, Gao S, Bai Y, Shar PA, Zhang W, Guo Z, Sun K, Fu Y, Huang C, et al: CancerHSP: Anticancer herbs database of systems pharmacology. Sci Rep 5: 11481, 2015.

8. Kreuger MRO, Grootjans S, Biavatti MW, Vandenabeele P and D'Herde K: Sesquiterpene lactones as drugs with multiple targets in cancer treatment: Focus on parthenolide. Anticancer Drugs 23: 883-896, 2012.

9. Ren Y, Yu J and Kinghorn AD: Development of anticancer agents from plant-derived sesquiterpene lactones. Curr Med Chem 23: 2397-2420, 2016.

10. Bosco A and Golsteyn RM: Emerging anti-mitotic activities and other bioactivities of sesquiterpene compounds upon human cells. Molecules 22: 459, 2017.

11. Zhou J and Zhang Y: Cancer stem cells: Models, mechanisms and implications for improved treatment. Cell Cycle 7: 1360-1370, 2008. 
12. Jordan CT: Searching for leukemia stem cells - not yet the end of the road? Cancer Cell 10: 253-254, 2006.

13. Kawasaki BT, Hurt EM, Kalathur M, Duhagon MA, Milner JA, Kim YS and Farrar WL: Effects of the sesquiterpene lactone parthenolide on prostate tumor-initiating cells: An integrated molecular profiling approach. Prostate 69: 827-837, 2009.

14. Efferth T, Sauerbrey A, Olbrich A, Gebhart E, Rauch P, Weber HO, Hengstler JG, Halatsch ME, Volm M, Tew KD, et al: Molecular modes of action of artesunate in tumor cell lines. Mol Pharmacol 64: 382-394, 2003.

15. Ji Y, Zhang YC, Pei LB, Shi LL, Yan JL and Ma XH: Anti-tumor effects of dihydroartemisinin on human osteosarcoma. Mol Cell Biochem 351: 99-108, 2011.

16. Gravett AM,Liu WM, Krishna S, Chan WC, Haynes RK, Wilson NL and Dalgleish AG: In vitro study of the anti-cancer effects of artemisone alone or in combination with other chemotherapeutic agents. Cancer Chemother Pharmacol 67: 569-577, 2011.

17. Zhang CZ, Zhang H, Yun J, Chen GG and Lai PB: Dihydroartemisinin exhibits antitumor activity toward hepatocellular carcinoma in vitro and in vivo. Biochem Pharmacol 83: 1278-1289, 2012.

18. Zografos AL and Anagnostaki EE: Sesquiterpenes. In: From Biosynthesis to Total Synthesis: Strategies and Tactics for Natural Products. John Wiley \& Sons, Inc., pp254-278, 2016

19. Anagnostaki EE and Zografos AL: 'Common synthetic scaffolds' in the synthesis of structurally diverse natural products. Chem Soc Rev 41: 5613-5625, 2012.

20. Anagnostaki EE and Zografos AL: Non-natural elemane as the 'stepping stone' for the synthesis of germacrane and guaiane sesquiterpenes. Org Lett 15: 152-155, 2013.

21. Anagnostaki EE, Demertzidou VP and Zografos AL: Divergent pathways to furosesquiterpenes: First total syntheses of (+)-zedoarol and (Rac)-gweicurculactone. Chem Commun (Camb) 51: 2364-2367, 2015.

22. Tseligka ED, Rova A, Amanatiadou EP, Calabrese G, Tsibouklis J, Fatouros DG and Vizirianakis IS: Pharmacological development of target-specific delocalized lipophilic cation-functionalized carboranes for cancer therapy. Pharm Res 33: 1945-1958, 2016.

23. Vizirianakis IS and Tsiftsoglou AS: Blockade of murine erythroleukemia cell differentiation by hypomethylating agents causes accumulation of discrete small poly(A)-RNAs hybridized to 3'-end flanking sequences of beta(major) globin gene. Biochim Biophys Acta 1743: 101-114, 2005.

24. Friend C, Scher W, Holland JG and Sato T: Hemoglobin synthesis in murine virus-induced leukemic cells in vitro: Stimulation of erythroid differentiation by dimethyl sulfoxide. Proc Natl Acad Sci USA 68: 378-382, 1971.

25. Vizirianakis IS, Wong W and Tsiftsoglou AS: Analysis of the inhibition of commitment of murine erythroleukemia (MEL) cells to terminal maturation by N6-methyladenosine. Biochem Pharmacol 44: 927-936, 1992.

26. Allen M, Bjerke M, Edlund $H$, Nelander $S$ and Westermark B: Origin of the U87MG glioma cell line: Good news and bad news. Sci Transl Med 8: 354re3, 2016.

27. Livak KJ and Schmittgen TD: Analysis of relative gene expression data using real-time quantitative PCR and the $2(-\Delta \Delta \mathrm{C}(\mathrm{T}))$ method . Methods 25: 402-408, 2001.

28. Dunham I, Kundaje A, Aldred SF, Collins PJ, Davis CA, Doyle F, Epstein CB, Frietze S, Harrow J, Kaul R, et al; ENCODE Project Consortium: An integrated encyclopedia of DNA elements in the human genome. Nature 489: 57-74, 2012.

29. Luo W and Brouwer C: Pathview: An R/Bioconductor package for pathway-based data integration and visualization. Bioinformatics 29 : $1830-1831,2013$.
30. Kanehisa M and Goto S: KEGG: Kyoto encyclopedia of genes and genomes. Nucleic Acids Res 28: 27-30, 2000.

31. Kanehisa M, Sato Y, Kawashima M, Furumichi M and Tanabe M: KEGG as a reference resource for gene and protein annotation. Nucleic Acids Res 44: D457-D462, 2016.

32. Kanehisa M, Furumichi M, Tanabe M, Sato Y and Morishima K KEGG: New perspectives on genomes, pathways, diseases and drugs. Nucleic Acids Res 45: D353-D361, 2017.

33. Gottesman MM, Lavi O, Hall MD and Gillet JP: Toward a better understanding of the complexity of cancer drug resistance. Annu Rev Pharmacol Toxicol 56: 85-102, 2016.

34. Hartwell JL and Abbott BJ: Antineoplastic principles in plants: Recent developments in the field. Adv Pharmacol Chemother 7: 117-209, 1969.

35. Ghantous A, Gali-Muhtasib H, Vuorela H, Saliba NA and Darwiche N: What made sesquiterpene lactones reach cancer clinical trials? Drug Discov Today 15: 668-678, 2010.

36. Merfort I: Perspectives on sesquiterpene lactones in inflammation and cancer. Curr Drug Targets 12: 1560-1573, 2011.

37. Lytton J, Westlin M and Hanley MR: Thapsigargin inhibits the sarcoplasmic or endoplasmic reticulum Ca-ATPase family of calcium pumps. J Biol Chem 266: 17067-17071, 1991.

38. Hehner SP, Heinrich M, Bork PM, Vogt M, Ratter F, Lehmann V, Schulze-Osthoff K, Dröge W and Schmitz ML: Sesquiterpene lactones specifically inhibit activation of NF-kappa B by preventing the degradation of I kappa B-alpha and I kappa B-beta. J Biol Chem 273: 1288-1297, 1998.

39. Ghantous A, Sinjab A, Herceg Z and Darwiche N: Parthenolide: From plant shoots to cancer roots. Drug Discov Today 18: 894-905, 2013.

40. Demertzidou VP and Zografos AL: Platinum-catalyzed cycloisomerizations of a common enyne: A divergent entry to cyclopropane sesquiterpenoids. Formal synthesis of sarcandralactone A. Org Biomol Chem 14: 6942-6946, 2016.

41. Foo K, Usui I, Götz DCG, Werner EW, Holte D and Baran PS: Scalable, enantioselective synthesis of germacrenes and related sesquiterpenes inspired by terpene cyclase phase logic. Angew Chem Int Ed Engl 51: 11491-11495, 2012.

42. Hu X, Xu S and Maimone TJ: A double allylation strategy for gram-scale guaianolide production: Total synthesis of (+)-mikanokryptin. Angew Chem Int Ed Engl 56: 1624-1628, 2017.

43. Warfel NA and El-Deiry WS: p21WAF1 and tumourigenesis: 20 years after. Curr Opin Oncol 25: 52-58, 2013.

44. Muñoz-Espín D and Serrano M: Cellular senescence: From physiology to pathology. Nat Rev Mol Cell Biol 15: 482-496, 2014.

45. Abbas T and Dutta A: p21 in cancer: Intricate networks and multiple activities. Nat Rev Cancer 9: 400-414, 2009.

46. Ventura A, Kirsch DG, McLaughlin ME, Tuveson DA, Grimm J, Lintault L, Newman J, Reczek EE, Weissleder R and Jacks T: Restoration of p53 function leads to tumour regression in vivo. Nature 445: 661-665, 2007.

47. Wu CH, van Riggelen J, Yetil A, Fan AC, Bachireddy P and Felsher DW: Cellular senescence is an important mechanism of tumor regression upon c-Myc inactivation. Proc Natl Acad Sci USA 104: 13028-13033, 2007.

48. Bretones G, Delgado MD and León J: Myc and cell cycle control. Biochim Biophys Acta 1849: 506-516, 2015. 